\title{
Telecolaboração e divergência em uma experiência de aprendizagem de português e inglês como línguas estrangeiras
}

Ricardo Augusto de Souza

Universidade Federal de Minas Gerais

\begin{abstract}
Este artigo propõe que um dos desafios encontrados por aprendizes de línguas, engajados com projetos de telecolaboração mediada pelo computador, diz respeito ao manejo das divergências entre seus próprios contextos de aprendizagem e os de seus colaboradores. Esse argumento será ilustrado por meio do relato de uma experiência de aprendizagem de português-inglês desenvolvida segundo os parâmetros de uma pedagogia da aprendizagem de línguas, mediada pelo computador denominada "aprendizagem em tandem". Na análise, será proposto que diferenças macrossociais entre 0 ensino de língua portuguesa na Austrália e o ensino de inglês no Brasil tenham sido insidiosas nos resultados do trabalho de telecolaboração.
\end{abstract}

This paper argues that one of the challenges facing language learners working in telecollaborative computer-mediated projects is dealing with the divergences they will find between their collaborators learning contexts and their own. This point will be illustrated through a report of a portugueseenglish language learning experience developed within the frame of a computer-assisted language learning pedagogy referred to as "tandem learning". In the analysis, it will be argued that macro-social differences between the teaching of Portuguese in Australia and the teaching of English in Brazil had an impact in the outcomes of the telecollaborative endeavour.

\section{Introdução}

Warschauer (1996) considera a internet o advento tecnológico de maior impacto e influência sobre o ensino/aprendizagem de línguas mediado pelo computador (CALL). ${ }^{1}$ Com a internet, tornou-se possível,

${ }^{1}$ CALL é a abreviatura da expressão em língua inglesa computer-assisted language learning. Segundo LEVY (1997), a expressão é usada para designar a busca e 0 estudo da aplicação do computador ao ensino e à aprendizagem de línguas. Dentre 
a um custo relativamente baixo e com razoável facilidade e rapidez, interagir com indivíduos ou grupos através dos sistemas de comunicação mediada pelo computador assíncrona e síncrona. G raças a esse tipo de comunicação, tornou-se viável a tomada de direções na prática de CALL que enfatizam o desenvolvimento de projetos pedagógicos sustentados em perspectivas colaborativas de aprendizagem, mas caracterizados pela distância geográfica que separa os participantes, e pela prevalência, em muitos casos absoluta, da comunicação por computador como meio de interação.

Concomitantemente à tecnologia que abre a possibilidade de colaboração a distância mediada pelo computador no ensino de línguas estrangeiras, surgem arcabouços teóricos de sustentação dessas propostas pedagógicas que corroboram sua colocação como inovação educacional. Warschauer \& Kern (2000), por exemplo, argumentam que o surgimento na década de 1990 do ensino de línguas baseado na rede (network-based language teaching) pode ser vinculado a mudanças de paradigma na história do ensino de línguas do século XX. Especificamente, esses autores sugerem que muito da prática contemporânea de ensino de línguas esteja sustentado por uma visão da aquisição de línguas que contempla a linguagem humana não apenas como um fenômeno individual e cognitivo, mas sim como um fenômeno construído socialmente. Assim, para Warschauer \& Kern (2000), a direção atual da prática de ensino de línguas informatizado, com sua ênfase na utilização da internet e da comunicação mediada pelo computador, está em grande parte afiliada a uma perspectiva de aquisição de línguas à qual esses autores dão a denominação de sociocognitiva.

Os proponentes dessa perspectiva sociocognitiva da aquisição de línguas, segundo Warschauer \& Kern (2000), advogam que o papel da instrução no ensino de línguas é proporcionar aos aprendizes oportunidades de experimentarem o discurso autêntico e socialmente adequado com o qual eles estariam também envolvidos quando

diversas outras abreviações usadas para designar essa área de interesse, tais como CAI (computer-assisted instruction), LEVY (1997) relata queCALL torna-se a designação consagrada na literatura a partir da década de 1980, quando se buscou englobar na área uma ampla diversidade de aplicações da informática na aprendizagem de línguas, e não apenas os tutores informatizados para exercícios de substituição e transformação de estruturas gramaticais que havia vigorado até aquela época. 
estivessem em comunidades discursivas externas à sala de aula. Para Warschauer \& Kern (2000), uma vez que a visão sociocognitiva da aquisição de línguas pode ser tomada como a fundamentação teórica do ensino de línguas baseado na rede, 0 advento da comunicação mediada por computador e a tecnologia do hipertexto podem ser tomados como seus proporcionadores no âmbito tecnológico. Através da nova modalidade de comunicação, do hipertexto e da World Wide Web (WWW), os aprendizes de línguas estrangeira têm tido a oportunidade de não apenas ter acesso a materiais de multimídia sobre assuntos de sua escolha e interesse, mas também de publicar seus próprios materiais e tomar parte ativamente em comunidades discursivas globais. Mas, sobretudo, por meio da comunicação mediada pelo computador, aprendizes de línguas estrangeiras têm tido a oportunidade de se engajar na comunicação síncrona e assíncrona com outros falantes de suas línguas-alvo e também com outros grupos e salas de aula que se tornam seus parceiros, abrindo, portanto, as portas para a promoção da aprendizagem colaborativa.

Um modelo de ap rendizagem colaborativa sustentada em recursos de comunicação através da internet, que tem sido praticado desde meados dos anos de 1990, é a aprendizagem de línguas em tandem. Assim como todos os modelos de aprendizagem telecolaborativa, a aprendizagem em tan dem encerra um caráter necessariamente multicultural. Neste artigo, será argumentado que, na aprendizagem de línguas em tandem, os aprendizes estão colocados perante a necessidade de se defrontar com diferenças trazidas à tona pelos ecos de trajetórias estudantis percorridas não só em contextos culturais, mas também em contextos educacionais, especificamente em contextos de ap rendizagem de línguas estrangeiras bastante distintos.

Na segunda parte do artigo, a aprendizagem de línguas em tandem será caracterizada. Na terceira parte, aspectos teóricos da aprendizagem de línguas, que se articulam com o modelo de telecolaboração ora examinado, serão discutidos. Na quarta parte, será descrita uma experiência de aprendizagem de português e inglês como línguas estrangeiras em tandem. Na quinta parte, algumas observações dessa experiência serão relatadas. Na sexta e última, serão tecidas considerações finais so bre a telecolaboração na aprendizagem de línguas estrangeiras. ${ }^{2}$

\footnotetext{
2 Este artigo sintetiza alguns dados e conclusões de minha tese de doutorado
} (SO UZA, 2003), defendida na UFMG e orientada naquela instituição pela Dra. 


\section{Caracterização da aprendizagem de línguas em tandem}

Por aprendizagem em tandem, entende-se a promoção de parcerias entre aprendizes falantes nativos de diferentes línguas, ambos interessados em aprender a língua do outro como L2 (cf. LITTLE \& BRAMMERTS, 1996; SCHWIENH ORST, 1998; APPEL, 1999; LITTLE et al., 1999). Trata-se de uma proposta de aprendizagem colaborativa, sendo essa dimensão explicitada na metáfora que lhe dá nome: tandem é a palavra inglesa usada para denominar bicicletas de dois assentos (tan dem bicycles), ou seja, bicicletas nas quais é o esforço conjunto dos dois ciclistas que as colocam em movimento.

Segundo Appel (1999), a aprendizagem em tandem implica colaboração e simultaneidade. Nela, os aprendizes encontram-se regularmente e trabalham conjuntamente para que cada um possa desenvolver a respectiva L2 através da interação entre eles estabelecida. Usualmente, na aprendizagem em tandem é proposta a resolução de tarefas conjuntas, assim como a constante troca de feedback e auxílio, havendo, porém, grande liberdade para os parceiros definirem suas próp rias metas e prioridades de aprendizagem. Os parceiros dividemse no uso da língua materna e da língua estrangeira de cada um, sendo que ambos terão, portanto, os papéis de aprendizes, interlocutores e informantes sobre sua língua e cultura.

A partir da segunda metade do século XX, a formação de parcerias bilingües com o objetivo de auxílio recíproco na aprendizagem das línguas dos parceiros ganhou ímpeto institucional e sistematização pedagógica. ${ }^{3}$ Brammerts (1996) menciona exemplos de formação de parcerias para aprendizagem de francês e alemão em tandem em colônias de férias para jovens franceses na Alemanha desde a década de 1960, e também a formação de parcerias entre estudantes de línguas estrangeiras e turistas

\footnotetext{
Vera Lúcia Menezes de O liveira e Paiva e pelo Dr. Robert Debski na Universidade de Melbourne, Austrália, onde trabalhei por um ano como bolsista do Programa de Doutorado com Estágio no Exterior, da CAPES.

${ }^{3}$ Entretanto, é interessante conjecturar que, tal como sugere BRAMMERTS (1996), a aprendizagem de uma língua estrangeira na circunstância em que duas pessoas, falantes de línguas diferentes, propõem-se a ajudar uma a outra na aprendizagem de suas línguas maternas seja, ainda que informal, talvez uma das práticas mais antigas de ensino/aprendizagem de línguas do mundo.
} 
em escolas de idiomas privadas em países como Espanha e Itália desde 1980. 0 autor sugere que 0 sucesso da aprendizagem em tandem pode ser atribuído ao fato de que esse tipo de arranjo de ensino/ aprendizagem tem o potencial de promover diversas condições favoráveis para a aprendizagem de línguas, tais como:

- O engajamento dos aprendizes em situações de comunicação autêntica.

- Minimização de possíveis inibições no uso da língua-alvo em função da alternação dos papéis de aprendiz e de falante proficiente.

- Oportunidades para que os aprendizes direcionem suas experiências de aprendizagem para que essas venham ao encontro de seus interesses prio ritários.

Desde o início dos anos 1990, a concep ção de aprendizagem em tan dem tem sido transferida também para o meio eletrônico, particularmente em função da comunicação através do email (cf. LEVY, 1997 e SCHWIEN HORST, 1998). Brammerts (1996), assim como Appel (1999), salientam que a transferência da idéia de colaboração em tandem na aprendizagem de línguas estrangeiras para o meio eletrônico trouxe a solução para o maior problema enfrentado na implementação desse tipo de proposta de aprendizagem: a grande dificuldade, por vezes encontrada, em estabelecer-se um regime de contatos presenciais freqüentes entre parceiros falantes nativos de línguas diferentes interessad os na aprendizagem da língua um do outro. A informatização da aprendizagem em tandem trouxe uma solução ao problema da formação das parcerias entre estudantes de línguas estrangeiras de origens geograficamente remotas de maneira contínua, freqüente e economicamente factível.

A aprendizagem em tandem é conceituada como sustentando-se em princípios ou aspectos específicos que norteiam sua implementação. Para seus proponentes, a essa modalidade de ap rendizagem subjazem expectativas quanto às atitudes dos aprendizes. Tais atitudes, ou princípios, devem ser cuidadosamente observadas para que se obtenha resultados positivos de aprendizagem. Schwienhorst (1998) propõe que sejam três os princípios fundamentais para a aprendizagem em tandem:

1. 0 princípio da reciprocidade: Cada aprendiz deve beneficiar-se igualmente da parceria, tendo a expectativa de tanto receber ajuda quanto oferecê-la. Há a necessidade de envolvimento e compromisso com o processo e com as necessidades do outro. 
2. O princípio do bilingüismo: Cada participante da parceria em tandem deve comprometer-se a um uso da língua estrangeira da qual ele é um aprendiz e de sua língua materna em proporções iguais.

3. 0 princípio da autonomia do aprendiz: Cada aprendiz é responsável por seu próprio processo de aprendizagem, pela delimitação de seus objetivos e dos melhores métodos para alcançá-los.

Esses três princípios formam um conjunto bem articulado de pressupostos e direcionamentos de atuação para os participantes dessa proposta pedagógica. Contudo, é o princípio da autonomia do ap rendiz que é tido como central para a aprendizagem em tandem. Os princípios da reciprocidade e do bilingüismo implicam a alocação de papéis alternados de aprendiz e de facilitador da aprendizagem aos estudantes de línguas que trabalham em tandem. A alternância de papéis, tal como teorizam Schwienhorst (1998) e D onaldson \& Kötter (1999), proporcionam o desenvolvimento de maior consciência por parte do aprendiz sobre a linguagem como um sistema, e sobre as dificuldades subjacentes ao processo de aprendizagem de uma língua estrangeira, o que tem 0 potencial de ajudar 0 aprendiz a continuamente planejar, monitorar e avaliar sua própria aprendizagem, assim como negociar suas necessidades e objetivos com seu parceiro, portanto o instrumentalizando para a autonomia na aprendizagem.

\section{Aspectos teóricos da aprendizagem de línguas em tandem}

Appel (1999) salienta a articulação da proposta de aprendizagem em regime de tandem com os fundamentos da abordagem comunicativa de aprendizagem de línguas. Baseando-se principalmente no modelo de competência comunicativa proposto em Canale \& Swain (1980), que incorpora a esse contructo as noções de competência gramatical, competência sociolingüística e competência estratégica, a autora sugere que a aprendizagem em tandem proporcione aos aprendizes nela envolvidos oportunidades de desenvolvimento da competência comunicativa por possibilitar-lhes amplo contato e uso da língua-alvo em situações reais, cujo propósito é a comunicação autêntica.

Ainda, por ter como aspecto central a promoção da colaboração entre aprendizes a distância, a aprendizagem em tan dem é conceituada por Schwienhorst (1998) e Appel (1999) em articulação com noção vygotskiana de "zona de desenvolvimento proximal". Para Vygotsky 
(1984), as estruturas mentais superiores ocorrem primeiramente no plano interpsicológico da interação. Esse autor argumenta que, na condução de tarefas, há uma discrepância entre o "nível de desenvolvimento real", caracterizado pelo desempenho que o indivíduo em amadurecimento de uma dada função cognitiva é capaz de ter sozinho, e o "nível de desenvolvimento potencial", ou seja, o seu desempenho quando assistido por outro indivíduo já amadurecido quanto àquela função cognitiva. Vygotsky (1984) nomeia a distância entre o nível de desenvolvimento real e o nível de desenvolvimento potencial como uma "zona de desenvolvimento proximal" (ZDP). A aprendizagem se dá nessa zona de desenvolvimento proximal, na qual a interação colaborativa permite que a função cognitiva, inicialmente desempenhada no âmbito interpsicológico da interação, seja paulatinamente transferida para o plano intrapsicológico do aprendiz.

Schwienhorst (1998) e Appel (1999) enfatizam que o tipo de interação mediada pelo computador, ocorrida entre os aprendizes envolvidos na aprendizagem em tandem, por ter como objetivo a colaboração recíproca para a comunicação em uma língua estrangeira, promove atividade dentro da ZDP e scaffolding ${ }^{4}$ continuados. A próp ria organização desse modelo de aprendizagem, com desempenho alternado dos papéis de aprendiz de língua estrangeira e falante proficiente (tutor/outro mais capaz) dos participantes, ilustra a centralidade dos pressupostos da interação e da colaboração nesse modelo de aprendizagem.

O utra característica própria da aprendizagem em tandem mediada pelo computador, que certamente não pode ser negligenciada, é o fato de que, na maior parte das experiências de implementação desta proposta pedagógica, a comunicação entre os parceiros se dá exclusivamente através da escrita.

\footnotetext{
${ }^{4}$ A noção de scaffolding é sugerida por BRUNER (1978), citado em APPEL (1999, p.5), e é entendida como o apoio cognitivo dado por um colega mais capaz ou por um tutor a um aprendiz ainda menos capaz de realizar individualmente certa tarefa. Esse apoio cognitivo é dado ao aprendiz menos capaz por seu envolvimento e interação com um tutor ou aprendiz mais capaz para a realização colaborativa de uma tarefa, naquele momento ainda além de sua capacidade de realização individual. A noção de scaffolding especifica a função de apoio cognitivo e colaboração da interação em atividades na ZDP.
} 
A comunicação por meio da escrita e a comunicação por meio da fala parecem engendrar formas distintas de processamento e de manipulação de mensagens, sendo que essas formas implicam operações cognitivas diferenciadas. Hildyard \& Olson (1982) argumentam que ouvintes e leito res parecem adotar estratégias diferentes na compreensão, e conseqüentemente na memorização do discurso oral e do discurso escrito. Esses autores sugerem que as estratégias utilizadas pelos ouvintes tendem a privilegiar o sentido do que foi ouvido, ou seja, os aspectos temáticos do discurso. Os leitores, por sua vez, por terem acesso a um registro permanente do discurso, podem deter-se nos detalhes dos enunciados que foram efetivamente produzidos, sejam esses cruciais ou não para a compreensão dos temas do discurso.

Chafe (1982) também argumenta que, nas circunstâncias de produção do discurso oral e do discurso escrito, processos cognitivos distintos estão atuando. Segundo esse autor, a própria velocidade com a qual se dá a fala e a escrita está ligada a diferenças nos processos subjancentes às duas modalidades de comunicação. Para Chafe (1982), na fala o processamento se constitui pela sucessão de idéias. ${ }^{5}$ Ele sugere que a expressão de idéias na fala seja geralmente constituída de cerca de seis palavras enunciadas com contornos intonacionais específicos, e usualmente envolva recursos léxico-gramaticais relativamente simples. Quanto à escrita, por outro lado, Chafe (1982) argumenta que a maior lentidão com a qual se dá a formulação de um texto escrito leva o escritor a poder sintetizar suas idéias em construções mais elaboradas e estruturalmente mais complexas. 0 autor sugere, ainda, que geralmente a escrita ocorre após a sucessão de idéias no pensamento, sendo, portanto, possível ao escritor refletir sobre elas. As o portunidades aumentadas de reflexão sobre a expressão, segundo o autor, tornam possível ao usuário da linguagem escrita a produção de enunciados nos quais há a articulação de mais de uma idéia.

A prevalência da expressão escrita, com as possíveis distinções cognitivas entre o processamento da escrita e o da fala, na comunicação mediada pelo computador, guarda interesse para a prática e a pesquisa

\footnotetext{
${ }^{5}$ Segundo CHAFE (1982), na fala tende a oco rrer um uso fragmentado da linguagem, no qual cada idéia é expressa através de uma única oração, usualmente constituída de um elemento predicativo (verbo ou adjetivo), e dos sintagmas nominais a ele associados com funções como sujeito ou objeto.
} 
sobre CALL. Kern (1996) comenta a respeito da utilização de email em projetos colaborativos que esse meio de comunicação através da escrita possibilita ao aprendiz a análise retrospectiva dos atos de comunicação e reflexão sobre eles, podendo, portanto, levá-los a maior consciência a respeito dos usos da língua-alvo no discurso social. Warschauer (1996) relata que, em discussões conduzidas por meio de sistemas de comunicação mediada pelo computador por ap rendizes de inglês como segunda língua, a análise dos enunciados produzidos revelou maior complexidade lexical e sintática do que a revelada em discussões semelhantes realizadas mediante a comunicação oral face a face.

Especificamente quanto à aprendizagem em tandem, Brammerts \& Little (1996) argumentam que a comunicação mediada pelo computador permite que cada participante das parcerias leia e analise as mensagens de seus parceiros com a potencial ajuda de diversos recursos (ex.: dicionários on-line), e que também preparem suas próprias mensagens com maior tempo de processamento do uso da linguagem. Schwienhorst (1998) argumenta que a escrita tem 0 potencial de abrir janelas sobre a linguagem e seus usos, tornando possível ao aprendiz maior reflexão sobre as diferenças e contrastes entre a primeira língua e a língua estrangeira. A conscientização sobre 0 sistema lingüístico e seus usos provavelmente conduz a avanços na interlíngua do aprendiz não somente na expressão escrita, mas também na expressão oral (cf. SCHWIENHORST, 1998; APPEL, 1999).

\section{A experiência de aprendizagem de português-inglês em tandem entre estudantes brasileiros e australianos}

Durante dez semanas do segundo semestre de 2001, um grupo de estudantes brasileiros e um grupo de estudantes australianos interagiram por meio de um ambiente virtual em um projeto de aprendizagem de línguas em tandem. Esses grupos eram formados por aprendizes de língua inglesa, estudantes da Faculdade de Letras da UFMG, em Belo Horizonte, e um grupo de aprendizes de língua portuguesa, em sua maioria vinculados a um curso eletivo desse idioma lecionado conjuntamente pelo Departamento de Espanhol de La Trobe University, na cidade de Melbourne, e pelo Horwood Language Centre, da Universidade de Melbourne. Até onde foi possível averiguar, à época do projeto, o curso 
eletivo das duas instituições de Melbourne era o único de língua portuguesa ministrado no sistema universitário australiano. No projeto denominado "Projeto de Aprendizagem de Português-Inglês em Regime de Tandem", buscou-se aplicar rigorosamente os princípios desse modelo de aprendizagem de línguas estrangeiras.

0 Projeto de Aprendizagem de Português-Inglês em Regime de Tandem aproximou, por meio da comunicação mediada pelo computador assíncrona, dois contextos de ensino e aprendizagem de línguas estrangeiras: 0 ensino de língua portuguesa na Austrália, e o ensino de língua inglesa no Brasil.

A língua portuguesa como língua estrangeira na Austrália é um exemplo do que, no sistema educacional daquele país, é denominado LOTE (acrônimo de Languages Other than English ou "línguas diferentes do inglês"). 0 ensino de LOTE na Austrália contempla diversos idiomas em vários níveis de escolarização nos sete estados e territórios do país, sendo os mais freqüentes, segundo dados em Baldauf, Jr.\& Mann (1992), 0 chinês mandarim, o indonésio, o japonês, o francês e o espanhol. Há na Austrália muita discussão sobre a eficiência, o custo e os resultados efetivos dos esforços de ensino de LOTE, com estudos sobre implementação de modelos instrucionais alternativos, tais como cursos intensivos e viabilização de intercâmbios estudantis (cf. Mann, 1992), e sobre a viabilidade e o impacto de inovações educacionais, tal como a aprendizagem de línguas mediada pelo computador (cf. Gassin, 1992).

Contudo, a língua portuguesa encontra-se em um subgrupo problemático das línguas estrangeiras ensinadas na Austrália. Trata-se das assim denominadas "LOTE de baixa demanda" ou Low Candidature LOTE. As LOTE de baixa demanda são cursos raramente ensinados nas universidades australianas, uma vez que, segundo Baldaulf Jr. (1995), esses são cursos de línguas estrangeiras cuja procura anual é inferior ao necessário para a cobertura dos custos de sua manutenção (estimado em torno de 10 a 12 alunos). De acordo com Barko (1995), os casos mais extremos de cursos caracterizáveis como LOTE de baixa demanda são usualmente ofertados por um único docente de um departamento, usualmente professor de alguma disciplina cognata ao ensino da língua de baixa demanda. O casionalmente, esse docente conta ainda com a ajuda de um professor contratado. $\mathrm{Na}$ análise do autor, esses cursos são mantidos por questões de tradição e de status passado, e, do ponto de vista administrativo, seu objetivo primário, e às vezes único, é a geração de recursos 
para sua sobrevivência. Barko (1995) menciona alguns exemplos de línguas ensinadas nessas circunstâncias: sânscrito, polonês e português.

O curso de português na Austrália era estruturado em dois níveis, iniciante e avançado, cada um deles coberto ao longo de do is semestres letivos. Em cada nível do curso, os alunos reuniam-se três vezes por semana, e suas aulas cobriam vocabulário e estrutura gramatical, prática de compreensão oral e fala, e aspectos culturais. Essas aulas eram ministradas por duas professoras: Maria Tereza, nascida em Portugal, professora efetiva do corpo docente do Departamento de Espanhol de La Trobe University, e Luciana ${ }^{6}$ nascida no Brasil, professora contratada para ministrar aulas no curso de português. A clientela típica do curso era formada por alunos que haviam viajado para o Brasil, geralmente exintercambistas, e também filhos de imigrantes portugueses na Austrália. Para matricular-se naquele curso, era pré-requisito que os alunos tivessem cursado um ano de uma língua românica, sendo, portanto, o curso de língua portuguesa um programa que exigia que a maioria de seus alunos se encontrassem no mínimo em seu segundo ano da universidade.

A situação do solitário curso de língua portuguesa do Horwood Language Centre e do Departamento de Espanhol de La Trobe University certamente discrepava fortemente da situação de um curso de língua inglesa oferecido no Brasil.

Em nosso país, a língua inglesa é ensinada com grande freqüência e em circunstâncias muito variadas. Essa realidade torna difícil estabelecer uma caracterização geral da situação do ensino do inglês no Brasil que se assemelhe a aqui resenhada para o ensino de língua portuguesa e das LOTE de baixa demanda no contexto australiano. Ainda, ela revela em si o que é provavelmente o aspecto mais contundente da referida discrepância.

A freqüência e diversidade de circunstâncias de ensino do inglês no sistema educacional brasileiro são indicativos da valorização desse idioma no país. Segundo Paiva (1996), a língua inglesa tem um valor simbólico na cultura brasileira, geralmente significando status social e engendrando para seus usuários a possibilidade de identificação com uma sociedade poderosa do ponto de vista político e econômico, a sociedade americana. Paiva (1996) compila exemplos da presença do inglês no cotidiano brasileiro, indicando a proliferação de seu uso como

\footnotetext{
${ }^{6}$ Trata-se de pseudônimos.
} 
produto de consumo e veículo publicitário. A autora sugere que a popularidade dos cursos e programas de ensino de inglês no Brasil é também motivada pelo status simbolizado pelo idioma.

Além do valor simbólico da língua inglesa na sociedade brasileira, a instrumentalidade desse idioma para diversas atividades profissionais colabora para a alta demanda por seu ensino e aprendizagem em nosso país. A língua inglesa é um código lingüístico de imensa relevância, por exemplo, para 0 acesso à informação e o intercâmbio nas áreas de ciência e tecnologia. Trata-se de uma relevância de modo algum circunscrita à realidade social brasileira, pois, como demonstra Crystal (1997), a língua inglesa adquiriu historicamente um papel central como veículo de divulgação da pesquisa científica e de transmissão e comercialização de tecnologia em âmbito global. Oliveira (1996) sustenta o ponto de vista de que a situação de falantes de uma língua pouco difundida para fins de comunicação internacional dos brasileiros nos deixa sem a opção de não ensinar outro idioma, se desejarmos evitar os danos econômicos e intelectuais do isolacionismo. Dada a importância do inglês no mundo, é compreensível que sua aprendizagem seja vista como quase essencial no Brasil.

0 projeto de aprendizagem de línguas em tandem que vinculou os estudantes australianos e brasileiros, foi estruturado a partir de três elementos constitutivos principais. Esses elementos foram o desígnio de tarefas, a utilização de um mecanismo de comunicação assíncrona (um sistema de bulletin board para as interações entre as parcerias), e o estímulo para que os participantes se engajassem na reflexão crítica sobre a pró pria ap rendizagem, sobre os eventos e incidentes do projeto e registrassem suas percepções em um diário on-line. Os textos desse diário eram enviados ao coordenador do projeto, que, subseqüentemente, os respondia. ${ }^{7}$

\footnotetext{
70 papel de "coordenador do projeto" foi desempenhado por mim. Em função da greve das universidades públicas federais deflagrada em 2001, os participantes brasileiros eram voluntários e não contavam com a orientação de um professor na época de sua participação. Ainda, como a experiência de um projeto de aprendizagem de línguas mediada pelo computador era nova para a Profa. Maria Tereza, minha participação como "professor virtual" no papel de coordenador do projeto foi uma solução adequada e conveniente.
} 
Especificamente no tocante às tarefas, buscou-se por meio delas engajar os participantes australianos e brasileiros em experiências de comunicação autêntica e que, ao mesmo tempo, viabilizassem a descoberta de aspectos da vida cotidiana nas cidades de Melbourne e de Belo Horizonte. Foram planejadas seis tarefas em português e seis tarefas equivalentes em inglês a serem executadas em prazos de uma semana. As tarefas em português e as tarefas em inglês alternavam-se semanalmente, portanto estabelecendo-se um cronograma de atividades para o projeto que, uma vez efetivamente observado, atualizasse o princípio do bilingüismo. Após modificações necessárias para que o projeto se adequasse ao calendário letivo das instituições australianas, as tarefas efetivamente realizadas foram as seguintes: ${ }^{8}$

QUADRO 1

\begin{tabular}{|c|c|}
\hline Tarefa/Task & Objetivos \\
\hline $\begin{array}{l}\text { Tarefa 1: Conhecendo seu parceiro. } \\
\text { Task 1: Getting to kn ow your partner. }\end{array}$ & $\begin{array}{l}\text { Descoberta de fatos sobre } \\
\text { a biografia do parceiro. }\end{array}$ \\
\hline $\begin{array}{l}\text { Tarefa 2: Planejamento de uma viagem } \\
\text { a Belo Horizonte. } \\
\text { Task 2: Planninga trip to Melbourne. }\end{array}$ & $\begin{array}{l}\text { Produção de um roteiro de } \\
\text { viagem para tempo e } \\
\text { orçamento limitados com } \\
\text { o auxílio do parceiro. }\end{array}$ \\
\hline $\begin{array}{l}\text { Tarefa 3: Comida em Belo Horizonte. } \\
\text { Task 3: Eatingin Melbourne. }\end{array}$ & $\begin{array}{l}\text { Produção de relatório } \\
\text { sobre hábitos alimentares } \\
\text { e restaurantes na cidade } \\
\text { do parceiro sob o ponto } \\
\text { de vista de um visitante. }\end{array}$ \\
\hline $\begin{array}{l}\text { Tarefa 5: Lendo o "Estado de Minas". } \\
\text { Task 5: Reading "TheAge". }\end{array}$ & $\begin{array}{l}\text { Leitura e discussão de } \\
\text { temas correntes na mídia } \\
\text { da região dos parceiros. }\end{array}$ \\
\hline $\begin{array}{l}\text { Tarefa 6: A vida universitária em Belo Horizonte. } \\
\text { Task 6: College life in Melbourne. }\end{array}$ & $\begin{array}{l}\text { Descoberta de fatos (base- } \\
\text { ando-se em um conjunto } \\
\text { de temas sugeridos) sobre } \\
\text { a universidade do parceiro. }\end{array}$ \\
\hline
\end{tabular}

${ }^{8} \mathrm{~A}$ tarefa quatro, na qual os participantes deveriam engajar-se na troca de informações sobre as culturas australiana e brasileira, foi omitida por parecer a mim e à Profa. Maria Tereza a mais trabalhosa e difícil. A necessidade de omissão de uma tarefa se deu em função do atraso do início das atividades do projeto resultante da situação de greve eminente na universidade brasileira, em agosto de 2001. 
Um ambiente para a web foi elaborado para dar sustentação à telecolaboração entre os estudantes australianos e os estudantes brasileiros. ${ }^{9} \mathrm{~A}$ noção balizadora de seu planejamento foi a busca de desenvolvimento de um ambiente eletrônico integrado para a aprendizagem em tandem, tal como proposta em Appel \& Mullen (2000). Segundo esses autores, um ambiente virtual que articula as diversas funcionalidades necessárias à aprendizagem em tan dem carrega a vantagem de focalizar o desempenho do aprendiz no tipo de tarefa necessário para essa modalidade de telecolaboração, simultaneamente proporcionando maior acesso a dados sobre os eventos trancorridos tanto aos professores e/ou coordenadores envolvidos no gerenciamento de parcerias quanto aos pesquisadores interessados na coleta desses dados.

Através do ambiente virtual do Projeto de Aprendizagem de Português-Inglês em Regime de Tandem, os participantes australianos e brasileiros podiam navegar por um conjunto de páginas bilingües, no qual a cada página em língua portuguesa correspondia uma página em língua inglesa. As páginas do ambiente davam acesso a instruções gerais para o projeto, a instruções detalhadas para cada uma das tarefas, ao ambiente que continha o sistema de comunicação assíncrona (bulletin board) e o diário on-line, e a um portal de acesso a outras páginas na internet de interesse para aprendizes de português e de inglês. A página que dá acesso ao menu de tarefas para os estudantes de língua portuguesa é ilustrada na figura a seguir:

\footnotetext{
${ }_{9}$ Disponibilizado na web no endereço $\underline{h t t p: / / w w w . g l e n . h l c . u n i m e l b . e d u . a u / ~}$ glen/tandem/.
} 


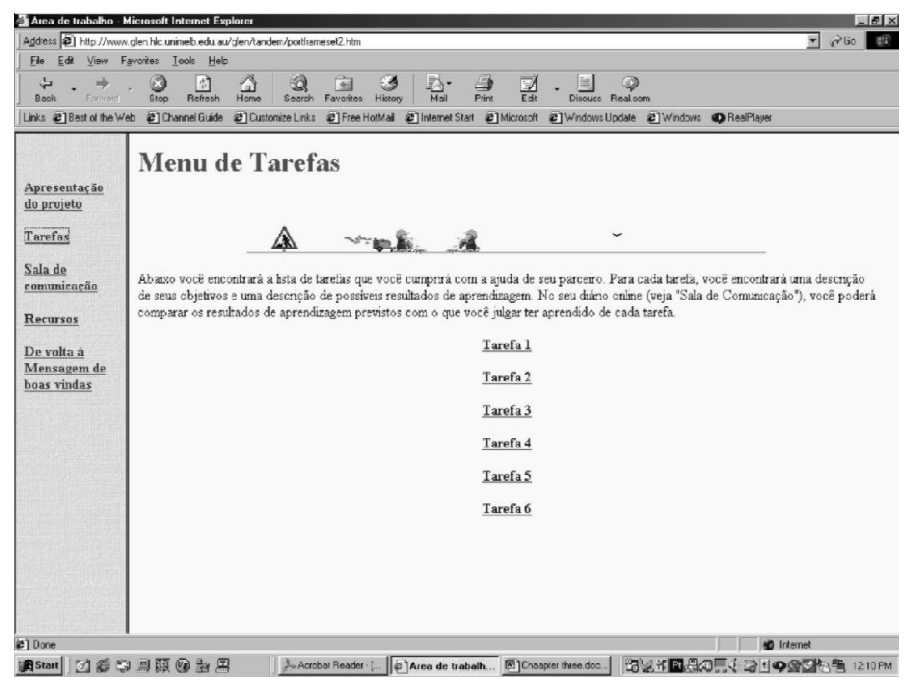

FIGURA 1 - Menu de tarefas em língua portuguesa

\section{Algumas observações das parcerias do Projeto de Aprendizagem de Português-Inglês em Regime de Tandem}

0 "Projeto de Aprendizagem de Português-Inglês em Regime de Tandem" foi estudado tendo-se como motivação o interesse de averiguar como as situações de afiliação dos aprendizes participantes tanto a culturas regionais quanto a culturas de aprendizagem diferentes poderiam nele estar se presentificando.

A investigação do projeto tandem adotou como design de pesquisa o "estudo de caso de base etnográfica". Esse design foi julgado adequado por apresentar soluções metodológicas para a observação e o registro de eventos em sua ocorrência natural, em seus contextos e circunstâncias autênticos (cf. NUNAN, 1992; YIN, 1994 e ANDRÉ, 1995). Tratava-se exatamente da intenção do estudo do projeto tandem, uma vez que nele não houve o isolamento de eventos ou controle de variáveis que pudessem ser-Ihes influentes. Os estudos de caso de base etnográfica caracterizam-se por neles ser adotada a análise de uma ampla base de dados para a configuração de uma descrição tão detalhada quanto possível dos eventos estudados. 
O banco de dados formado para o estudo do projeto tandem foi originado a partir de seis fontes distintas, quais sejam:

1. Mensagens trocadas entre os parceiros no bulletin board.

2. Notas do diário on-line e réplicas do coordenador do projeto.

3. Questionários distribuídos aos participantes sobre suas expectativas e experiências como aprendizes de línguas estrangeiras.

4. Entrevistas presenciais e on-line com os participantes.

5. Entrevista com a Profa. Maria Tereza.

6. Notas de campo registradas ao longo do projeto tandem.

Foram analisados dados oriundos de três duplas e de um trio formado por dois estudantes australianos e uma estudante brasileira. A formação de um trio ocorreu em função de ajustes excepcionais necessários para a configuração das parcerias após desistências de participantes das duas nacionalidades. Contudo, a maior parte da atividade do trio transcorreu de fato entre a estudante brasileira e um estudante australiano.

A observação dos eventos dessas quatro parcerias de aprendizagem de línguas em tandem revelou um padrão interessante de assimetria. A realização dos princípios teóricos da aprendizagem em tandem foi bastante exemplificada nas parcerias formadas com a participação de estudantes australianos voluntários. Por outro lado, as parcerias formadas por estudantes australianos regularmente matriculados no curso de português apresentaram diversas irregularidades e afastamentos dos pressupostos dessa modalidade de telecolaboração.

As parcerias formadas por alunos matriculados no curso australiano de língua portuguesa contavam com a participação de estudantes cujas atitudes e motivações para os estudos desse idioma eram bastante singulares, tal como revelado por eles próprios em suas entrevistas e respostas aos questionários, assim como expresso nas percepções da Profa. Maria Tereza em entrevista.

Um desses estudantes buscava no curso de português oportunidades de manter vivo um vínculo com o Brasil, país que ele visitara como intercambista. Contudo, esse estudante não tinha interesse maior em verdadeiramente avançar seus conhecimentos da língua portuguesa. Em sua atuação, esse estudante não observou o cronograma de tarefas e de mudança de código lingüístico, tendo se preocupado, na maior parte do tempo, em engajar-se em interações casuais com sua parceira 
brasileira. Esta, por sua vez, valeu-se mais dos recursos do ambiente virtual do que propriamente da interação para informar-se do conteúdo das tarefas e para realizá-las. Ao fim do projeto, ambos os participantes relataram desconhecer quais seriam os interesses de aprendizagem do outro, revelando afastamento do princípio da reciprocidade subjacente à teorização da aprendizagem em tan dem, e, portanto, de sua natureza colaborativa.

Outra participante australiana, filha de imigrantes portugueses na Austrália, via no curso de português uma oportunidade de minimização de seus esforços para a obtenção de seu diploma de graduação, tal como ela mesma deixava explícito para a professora de português, para sua parceira brasileira, e em sua entrevista comigo. Essa participante pouco se interessava em enviar mensagens em língua portuguesa, uma vez que tal procedimento, como ela pró pria relatou, não seria avaliado. Ela revelou motivação apenas na tarefa inicial, na qual ela interagia com sua parceira brasileira para que elas se conhecessem. Os assuntos abordados, majoritariamente em mensagens em inglês, eram gostos pessoais, aspirações, relacionamentos, rapazes, etc. A parceira brasileira, por outro lado, preocupava-se desde o início do projeto com a adoção de estratégias que consolidassem os resultados de aprendizagem. Tanto a postura de sua parceira australiana a incomodava quanto sua postura era vista pela australiana como reflexo de expectativas exageradamente altas. 0 desenlace da interação das parceiras foi o conflito e posterior rompimento antes do fim do projeto.

Nessas duas parcerias, os estudantes de língua portuguesa eram alunos de um curso de línguas estrangeiras em relação ao qual nutriam a expectativa de que fosse "fácil", expectativa até certo ponto corroborada pelas circunstâncias geradas pela falta de prestígio de seu ensino.

Os participantes australianos voluntários das parcerias distoaram dos alunos efetivamente matriculados no curso de português por representarem estudantes desse idioma que, em sua entrevista, a Profa. Maria Tereza mencionou estarem ficando raros. Tratava-se de alunos efetivamente motivados pelo vislumbre de possibilidades a lhes serem abertas pelos estudos daquela "incomum" língua estrangeira.

No caso específico dos australianos voluntários do projeto tan dem, esses estudantes nutriam expectativas de viagem, de contatos com falantes do português e de obtenção de oportunidades de trabalho em países de língua portuguesa, particularmente no Brasil. As 
aspirações trazidas por esses estudantes australianos para suas experiências de aprendizagem de português, dentre elas o projeto tandem, guardavam maior semelhança com a funcionalidade geralmente atribuída à aprendizagem do inglês como língua estrangeira pelos estudantes brasileiros.

Uma participante voluntária, tal como ela explicou em sua entrevista e revela em uma de suas mensagens para sua parceira brasileira, valorizava muito as oportunidades de comunicação com falantes do português. Ela se sentia fortemente motivada pela aprendizagem de vocabulário e expressões idiomáticas. No início do intercâmbio de mensagens entre as duas participantes, a brasileira solicitou que elas trocassem feedback e correções sobre o uso das línguas estrangeiras, pedido prontamente atendido pela australiana. Ao longo do projeto, a participante australiana, que era falante nativa do espanhol e imigrara para a Austrália com a família na adolescência, escreveu em seu diário on-line que a releitura de suas mensagens no bulletin board faziam com que ela aprimorasse tanto seu uso do português como seu uso do inglês. Esse relato ilustra com clareza a possibilidade de conscientização sobre aspectos do uso da língua pela interação através da escrita em meio virtual.

A possibilidade de interação sistemática e uso da língua portuguesa com outro falante dessa língua foi também celebrada pelo outro estudante voluntário australiano, que desejava oportunidades de aprendizagem além das proporcionadas por livros didáticos. Esse estudante desenvolveu com sua parceira brasileira, uma entusiasta do uso de computadores e da internet na aprendizagem de línguas estrangeiras, um sistema de auxílio na troca de informações culturais pertinentes às tarefas do projeto e de ensino de itens lexicais e até aspectos pragmáticos de uso de suas línguas-alvo. 0 australiano relatou em seu diário on-line como a experiência de redigir as tarefas e comunicar-se em português levavam-no a aprender questões específicas da estrutura gramatical da língua portuguesa. Os princípios da reciprocidade e da autonomia foram ilustrados na interação dessa parceria, na qual inclusive resoluções de atrasos no cumprimento das tarefas eram negociadas pelos parceiros integralmente através de sua comunicação eletrônica. 


\section{Considerações finais}

As propostas telecolaborativas em aprendizagem de línguas estrangeiras, nas quais se insere o regime de tandem, abrem possibilidades sem precedentes de que se estabeleçam contatos com facetas das mais diversas culturas. Do ponto de vista da aprendizagem de uma língua estrangeira, as chances de interlocução instauradas são de um valor por certo irrefutável. Tal como sugerem Donaldson \& Kötter (1999), subjacentemente à telecolaboração, há uma metáfora de transporte à cultura-alvo.

Contudo, um aspecto que não pode ser negligenciado é o de que, conjuntamente com a aproximação dos mais múltiplos aspectos de práticas socioculturais diversas, a telecolaboração para fins pedagógicos aproxima igualmente dois contextos de aprendizagem. No tocante às línguas estrangeiras, um projeto de telecolaboração coloca em contato circunstâncias diferentes de aprendizagem de línguas, inseridas em esferas macrossociais para cuja configuração competem variáveis, segundo van Lier (1988), tais como o valor atribuído à instituição de ensino, as atitudes e afiliações identitárias dos estudantes e o status relativo entre a língua local e a língua estrangeira. Para van Lier (1988), o conjunto dos acontecimentos do cotidiano dos agentes envolvidos nas salas de aula tem repercussões sobre o que transcorre nas situações de aprendizagem.

A aprendizagem em tandem coloca para os aprendizes nela envolvidos o requerimento de que eles tenham que defrontar-se com diferenças oriundas da vivência de seus parceiros em realidades de aprendizagem de línguas diferentes. Igualmente, ela traz o requerimento de que eles venham a contorná-las em prol da realização de seus objetivos de aprendizagem e do auxílio à realização dos objetivos de seus parceiros.

Essa conclusão encontra ressonâncias em estudos que explicitam a incidiosidade dos contextos sociais sobre as experiências de aprendizagem de línguas estrangeiras. Holliday (1994), por exemplo, salienta a relevância da análise do contexto social macro para a compreensão do contexto social micro das interações e da dinâmica de grupo nas salas de aula de língua inglesa. Segundo o autor, essa compreensão deve ter como elemento norteador o reconhecimento de que as salas de aula inserem-se em ambientes próprios, tais como, por 
exemplo, instituições de ensino públicas ou privadas, que, por sua vez, se inserem em conjunturas educacionais condicionadas por políticas específicas ou por configurações das forças de mercado. Somam-se a influência de fatores, tais como condições econômicas locais e disponibilidade de recursos para o ensino de línguas. Para Holliday (1994), esses aspectos contextuais marcam profundamente e especificam a realidade de cada sala de aula, o que torna cada configuração de ensino e aprendizagem de línguas uma experiência radicalmente singular.

Essa perspectiva é igualmente contemplada por Cortazzi \& Jin (1996) em um exame das divergências da cultura de aprendizado de línguas trazidas para circunstância de ensino e ap rendizagem em que alunos e professores pertecem a afiliações socioculturais diversas. Os autores demonstram que, em situações nas quais essas diferenças se instalam, as interpretações e os significados atribuídos às ações e aos papéis de professores e alunos por esses próprios agentes são fortemente discrepantes.

No Projeto de Aprendizagem de Português-Inglês em Regime de Tandem aqui relatado, sem dúvida, esse contato entre circunstâncias diferentes de aprendizagem de línguas se operou. Nele, aproximaramse dois espaços. Um deles era habitado pelos poucos alunos do curso de uma língua "exótica", classificado como de baixa demanda, o português no sistema universitário australiano. Ensinando em um curso ofertado como carga horária eletiva e sob constante ameaça de encerramento por insuficiência de alunos, os professores de português como língua estrangeira naquele contexto chegavam a ficar impedidos de fazer maio res exigências de desempenho acadêmico dos alunos, sob pena de baixar ainda mais sua procura. ${ }^{10} O$ outro espaço era habitado por estudantes brasileiros de língua inglesa. Trata-se de uma língua estrangeira que, além de seu altíssimo prestígio em âmbito global, é, no Brasil, especialmente simbolizadora de status econômico e social. Particularizava ainda mais esse espaço o fato de que seus habitantes eram estudantes de Letras, situação que provavelmente acentuava o

\footnotetext{
${ }^{10}$ Informação obtida através de relatos da Profa. Maria Tereza acerca do cotidiano do curso de português por ela lecionado na Austrália (Notas de campo do pesquisador).
} 
caráter promissor da aprendizagem de inglês para eles, assim como talvez sua motivação para o envolvimento em experiências de aprendizagem de línguas.

Certamente, os encontros e também os desencontros do Projeto de Aprendizagem de Português-Inglês em Regime de Tandem exemplificam o que pode ocorrer em outras situações de telecolaboração. A comunicação mediada pelo computador viabiliza uma ap roximação de mundos distantes na formação de comunidades virtuais de aprendizagem. Contudo, a comunicação mediada pelo computador não neutraliza suas diferenças. Provavelmente, até mesmo na aproximação de duas instituições dentro do mesmo país, haverá a aproximação de espaços distintos, resultantes da complexidade das determinações na interface entre vários fatores macrossociais e os eventos microssociais das interações nas experiências de aprendizagem.

Assim, uma direção aparentemente fecunda para a telecolaboração na aprendizagem de línguas, seja ou não o modelo pedagógico o regime de tandem, é seu aproveitamento no desenvolvimento do que Cortazzi \& Jin (1996) denominam "sinergia cultural": a instrumentalização dos ap rendizes para a percep ção e compreensão de valores e atitudes divergentes, sem entretanto haver perda das atitudes e dos papéis próprios.

Um projeto de aprendizagem telecolaborativa deve idealmente incluir o reconhecimento, a reflexão e a descoberta das realidades e ambientes de aprendizagem dos participantes envolvidos por parte de professores e alunos, tranformando-os em potenciais etnógrafos. Certamente, esse seria um objetivo educacional condizente com 0 ensino de línguas estrangeiras através da adoção de tecnologias de comunicação pela internet, uma vez que dele surge com especial força a possibilidade da comunicação intercultural. Afinal, o encontro com as mais diversas contingências além das paredes das salas de aula e a aprendizagem da convivência com as divergências parecem ser a vocação da adoção para a aprendizagem de línguas estrangeiras da tecnologia que tem ajudado a tornar o mundo menor. 


\section{Referências}

ANDRÉ, Marli Eliza D. A. de. Etnografia da prática escolar. Campinas: Papirus Editora, 1995. 132p.

APPEL, Marie C. Tandem language learning via e-mail: some basic principles and a case study. CLCS occasional paper n. 54. Dublin: Trinity College, Centre for Language and Communication Studies, 1999.

APPEL, Marie C. \& MULLEN, Tony. Pedagogical considerations for a webbased tandem language learning environment. Computers\& Education 34, 2000, p. 291-308.

BALDAUF, JR., Richard B. (O rg.). Viability of Low Candidature LOTE Courses in Universities. Canberra: Australian Government Publishing Services, 1995. 180p.

BARKO, Ivan. Low Candidature LOTE Courses in Universities. In: BALDAUF, JR., Richard B. (Org.). Viability of Low Candidature LOTE Courses in Universities. Canberra: Australian Government Publishing Services, 1995.

BRAM MERTS, Helmut. Language Learning in Tandem Using the Internet. In: WARSCHAUER, Mark (O rg.). Telecollaboration in foreign language learning. Manoa: University of Hawai'l Press, 1996.

CANALE, Michael \& SWAIN, Merril. Theoretical bases of communicative approaches to second language teaching and testing. Applied Linguistics, v. 1, n. 1, p. 1-47, 1980.

CHAFE, Wallace L. Integration and involvement in speaking, writing, and oral literature. In: TANNEN, Deborah (O rg.). Spoken and written language exploring orality and literacy. Norwood: Ablex Publishing Corporation, 1982.

CORTAZZI, Martin; JIN, Lixian. Cultures of learning: Language classrooms in China. In: COLEMAN, Hywel (O rg.). Society and the language classroom. Cambridge: Cambridge University Press, 1996.

CRY STAL, David. English as a global language. Cambridge: Cambridge University Press, 1997.

DONALDSON, Randall P.; KÖTTER, Markus. Language Learning in Cyberspace: teleporting the classroom into the target culture. CALICO Journal, v. 16, n. 4, p. 531-558, 1999. 
HILDYARD, Angela; OLSON, David R. On the comprehension and memory of oral vs. Written discourse. In: TANNEN, Deborah (Org.). Spoken and written language - Exploring orality and literacy. Norwood: Ablex Publishing Corporation, 1982.

HOLLIDAY, Adrian. Appropriate methodology and social context. Cambridge: Cambridge University Press, 1994.

LEVY, Michael. Computer-assi sted language learning - context and conceptualization. Oxford: Claredon Press-Oxford University Press, 1997.

LITTLE, David et al. Evaluating tandem language learning by e-mail. Report on a bilateral project. CLCS occasional paper $n$. 55. Dublin: Trinity College, Centre for Language and Communication Studies, 1999.

LITTLE, David; BRAMMERTS, Helmut. A guide to language learning in tandem via the internet. CLCS occasional paper $n$. 46. Dublin: Trinity College, Centre for language and Communication Studies, 1996.

NUNAN, David. Research methods in language learning. Cambridge: Cambridge University Press, 1992.

OLIVEIRA, Solange Ribeiro de. Ideologia e ensino de línguas e literatura estrangeiras. In: PAIVA, Vera L. Menezes O . (O rg.). Ensino delíngua inglesa - reflexões e experiências. Campinas/Belo Horizonte: Pontes Editores/ Departamento de Letras Anglo-Germânicas da UFMG, 1996.

PAIVA, Vera L. Menezes O. Paiva. A língua inglesa no Brasil e no mundo. In: PAIVA, Vera L. Menezes O (Org.). Ensino delíngua inglesa - reflexões e experiên cias. Campinas/Belo Horizonte: Pontes Editores/Departamento de Letras Anglo-Germânicas da UFMG, 1996.

SILVERMAN, D avid. Interpreting QualitativeData - $2^{\text {nd }}$ edition. Thousand Oaks: Sage Publications, 2001. 325p.

SCHWIENHORST, Klaus. Matching pedagogy and technology - Tandem learning and learner autonomy in online virtual language environments. In: SOETAERT, R.; DE MAN, E., VAN BELLE, G. (Org.). Languageteaching on-line. Ghent: University of Ghent, 1998

SOUZA, Ricardo Augusto. Aprendizagem de línguas em tandem: estudo da telecolaboração mediada pelo computador. 2003. Tese (D outorado em Língüística Aplicada) - Faculdade de Letras da UFMG, Belo Horizonte. 
VYGOTSKY, Lev S. A formação social da mente. (Tradução de José Cipolla Neto, Luís Silveira Menna Barreto e Solange Castro Afeche - Grupo de Desenvolvimento de Ritmos Biológicos do Departamento de Ciências Biomédicas da USP - da tradução em inglês Mind and Society - The Development of Higher Psychological Processes). São Paulo: Martins Fontes, 1984.

WARSCHAUER, Mark. Computer-mediated collaborative learning: theory and practice. Modern Language Journal, v. 81, n. 3, p. 470-481, 1997.

WARSCHAUER, Mark; KERN, Richard (Org.). Network-based Language Teaching: Concepts and Practice. Cambridge: Cambridge University Press, 2000.

VAN LIER, Leo. Interaction in thelanguage curriculum. Harlow: AddisonWesley Longman Limited, 1988.

YIN, Robert K. Case study research: design and methods (2 ${ }^{\text {nd }}$ Edition). Thousand Oaks: Sage Publications, 1994. 171p. 